\title{
IBD epidemiology: Ongoing issues and new ideas. The Canadian perspective
}

\author{
ABR THOMSON, MD, PHD, FRCPC, FACP, FRS, FACG
}

\begin{abstract}
ABR THOMSON. Inflammatory bowel disease epidemiology: Ongoing issues and new ideas. The Canadian perspective. Can J Gastroenterol 1993;7(2): 142-148. The prevalence of inflammatory bowel disease (IBD) in Canada is increasing, especially for patients with Crohn's disease and for young women living in urban areas. The number of IBD patients varies widely across Canada, especially for Crohn's disease. Epidemiological studies have suggested that there may be an environmental, as well as a familial, factor in the pathogenesis of IBD, but it is not clear where the next breakthrough will occur. The cost to the patient is high, and the cost to society is alarming and increasing. Thankfully, medical and surgical therapy is improving, but when do we break the code, where do we get that lucky break, that long-awaited breakthrough?
\end{abstract}

Key Words: Canadian perspective, Epidemiology, Inflammatory bowel disease

\section{Questions épidémiologiques et diagnostiques dans la maladie intestinale inflammatoire: perspective canadienne}

RÉSUMÉ: La prévalence de la maladie intestinale inflammatoire augmente au Canada, particulièrement chez les patients atteints de maladie de Crohn et chez les jeunes femmes des régions urbaines. Le nombre de malades atteints de maladie intestinale inflammatoire varie considérablement au Canada, particulièrement pour ce qui est de la maladie de Crohn. Des études épidémiologiques ont suggéré le rôle possible de facteurs environnementaux et familiaux dans la pathogenèse de la maladie intestinale inflammatoire, mais on ignore dans quel domaine s'accomplira la prochaine percée. Le coût est très élevé pour le patient, et ne cesse de croître pour la société, atteignant des taux alarmants. Heureusement, le traitement médical etchirurgical s'améliore, mais la clef du mystère nous échappe encore.
C HRONIC IDIOPATHIC ULCERATIVE colitis and Crohn's disease are serious and perplexing chronic intestional disorders. In the past 10 years much work has been done to identify new therapeutic modalities, surgical techniques have been advanced, the importance and role of nutritional
Nutrition and Metabolism Research Group, Division of Gastroenterology, University of Alberta, Edmonton

Correspondence and reprints: Dr ABR Thomson, 519 Robert Newton Research Building, University of Alberta, Edmonton, Alberta T6G 2C2. Telephone (403)492-6490

Fax (403)492-7964 therapy has been emphasized, and immunological and microbiological work has been undertaken in an attempt to determine the etiology of inflammatory bowel disease (IBD). Why then does there continue to be interest in the epidemiology of IBD (1)? Such work helps one to determine the size of the clinical problem and the potential impact on community health care delivery, the hospital-based impact, the training required for physicians and other health professionals, and the development of a rational funding base for continued research efforts. Epidemiological studies have also been used in an effort to determine clues of the possible etiology and cure of IBD. Considered possible etiological factors include contagion, childhood factors, smoking, medications, diet, genetic aspects and factors associated with relapses. Time-space clustering studies do not support the concept that there is an infectious agent responsible for the development of IBD $(2,3)$ but, of course, careful microbiological work continues to attempt to identify a possible contagion.

\section{POSSIBLE PATHOGENESIS}

Exogenous factors in Crohn's disease have been critically reviewed (4). Three of six studies have suggested that persons with Crohn's disease were breastfed for shorter periods than usual, if at all (5-10). Increased consumption of refined carbohydrates $(5,11-14)$, 
cigarette smoking (14-18) and the use of oral contraceptive agents (OCA) $(17-19)$ may be associated with IBD occurrence, although the association between OCA use and ulcerative colitis has been challenged (20-22). Methodological problems were inherent in some studies looking at the question of sugar consumption in patients with Crohn's disease. When these potential problems were addressed, one carefully conducted study found an insignificant, while another a significant, increase in sugar use $(23,24)$. While a number of reports have suggested an association between the use of OCA and IBD, this has not been confirmed for Crohn's disease (21) or ulcerative colitis $(20,22)$.

Cigarette smoking is associated with an increased incidence of disease by factors ranging from 1.8 (14) to 4.8 (25). Smokers have a higher incidence of Crohn's disease in a dose-dependent fashion (26), and smoking is associated with an increased risk of recurrence (27), including after surgery (28). Curiously, in 18 monozygotic twins who had at least one sibling with Crohn's disease, smoking was not found to be associated with concordance of disease (29). The ulcerative colitis/ nonsmoking and the Crohn's disease/ smoking association has been examined by meta-analysis and against causality criterion for chronic diseases (30). In northern Alberta, smokers more likely have Crohn's disease than ulcerative colitis $(22,31)$. These environmental factors, however, seem to play only mediating roles rather than being directly involved in the etiology of IBD.

A variety of medications have been examined for their possible association with IBD, including analgesics, nonsteroidal anti-inflammatory drugs (NSAIDs), OCA and ethanol. The development of IBD is not associated with ethanol use (31). NSAIDs may produce inflammatory lesions of the small intestine which may be distinctive or may mimic IBD (32-34). Patients with known IBD may relapse during treatment with NSAIDs (35-37).

The importance of nutritional assessment and dietary correction of deficiencies is well recognized in IBD, and there is a growing use of diet therapy $(38,39)$ and elemental diets (40) in IBD therapy. While there may be multiple nutrient deficiencies in patients with IBD (41-43), there does not appear to be a deficiency in the intake of fibre or sugar, and there does not appear to be any confirmed abnormal intake of toothpaste $(44,45)$ or corn flake cereal (46).

There is a general suspicion that genetic factors may be involved in the pathogenesis of IBD. It is well-recognized that approximately one patient in six with IBD will have an affected family member, and this association tends to be higher in the daughters and sisters of index female patients (47). Spousal IBD is rare (48), including a Canadian example (49). There is a higher risk of IBD if both parents had already developed IBD at the child's conception (48). Twin studies (29) in monozygotic and dizygotic twins have shown disease concordance, with a higher proband concordance rate among monozygotic twins with Crohn's disease $(58.3 \%)$ than in those with ulcerative colitis (6.3\%).

Certain human lymphocyte antigen alleles may be more common in patients with IBD, such as A2 in Crohn's disease and BW35 in ulcerative colitis. One colonic glycoprotein (HCM species IV) is reduced in patients with ulcerative colitis, independent of the inflammatory activity; this reduction also occurs in unaffected monozygotic twins (50). The composition of mucin in Crohn's disease patients and their unaffected twins was not significantly different from controls.

The initial suggestion of an increase in intestinal permeability in relatives of patients with IBD (51) may not be for all probes or for all studies of intestinal permeability (52-54).

\section{WHO ARE AFFECTED?}

What is the size of the problem of IBD? Who are the patients who are at risk of developing Crohn's disease and ulcerative colitis? The usual epidemiological considerations are of incidence and time trends, age and gender of the patient, urban versus rural distribution, assessment of geographic patterns, educational attainment and ethnic variation. In such studies there is the problem of case identification, with the possibility of overestimating IBD patients (eg, including persons with irritable bowel syndrome or acute colitis). Furthermore, there is the possibility of underestimating the incidence of IBD because of the (unfortunately) frequent long intervals between the onset of symptoms and clinical diagnosis.

Factors predicting relapse: What are some of the factors which predict a relapse of IBD? Recurrence is frequent after surgery for Crohn's disease (55) or after a recent upper respiratory tract infection in patients with previously diagnosed ulcerative colitis (36). In patients with ulcerative colitis, a recent diarrhea episode, antibiotic ingestion or stressful life events do not appear to predict a recurrence. Relapse does show a seasonal pattern: higher rates of recurrence from August to January than from January to July (56) are noted. Recent ingestion of analgesics such as NSAIDs or acetominophen may predict a recurrence $(35,37)$. For most patients, however, it is unknown why they have a symptomatic recurrence at any given point. In fact, sometimes the recurrent intestinal symptoms in a patient with known IBD may be not so much from IBD, but rather from a superimposed irritable bowel syndrome (57).

World trends in demography of IBD: There are a variety of methods which have been used to identify patients with IBD, including mortality and hospital admission rates, and outpatient visits. From a composite of the world literature, the total incidence of ulcerative proctitis, ulcerative colitis and Crohn's disease is six to 20 per $10^{5}$ population, with a range of prevalences reported between 90 and 300 per $10^{5}$ population (58). The incidence and prevalence of ulcerative colitis appears to be stable, whereas that of Crohn's disease is increasing. These differences are not due just to improved diagnostic methods, or methods used to better distinguish between Crohn's disease and ulcerative colitis. The increased incidence of ulcerative colitis between 1965 and 1980 


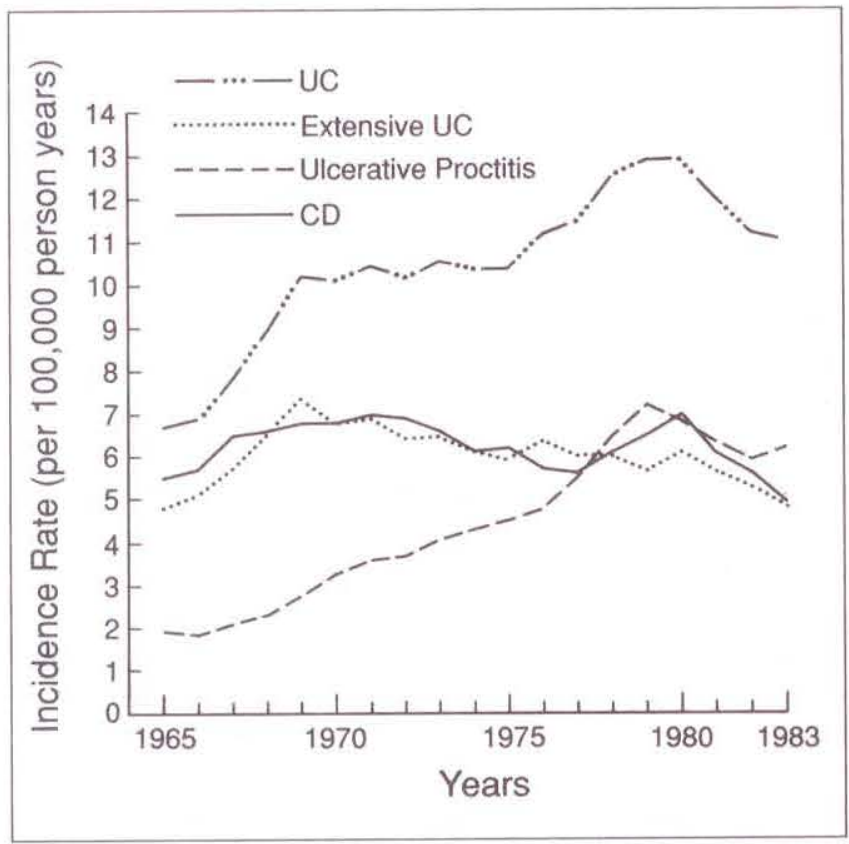

Figure 1) Age-adjusted annual incidence rates for ulcerative colitis (UC), extensive UC, ulcerative proctitis and Crohn's disease (CD), in Uppsala, Sweden from 1965-83 (moving three-year average is adjusted to the 1970 Swedish population) (Reproduced with permission from Ekbon et al. Gastroenterology 1991;100:350-8)

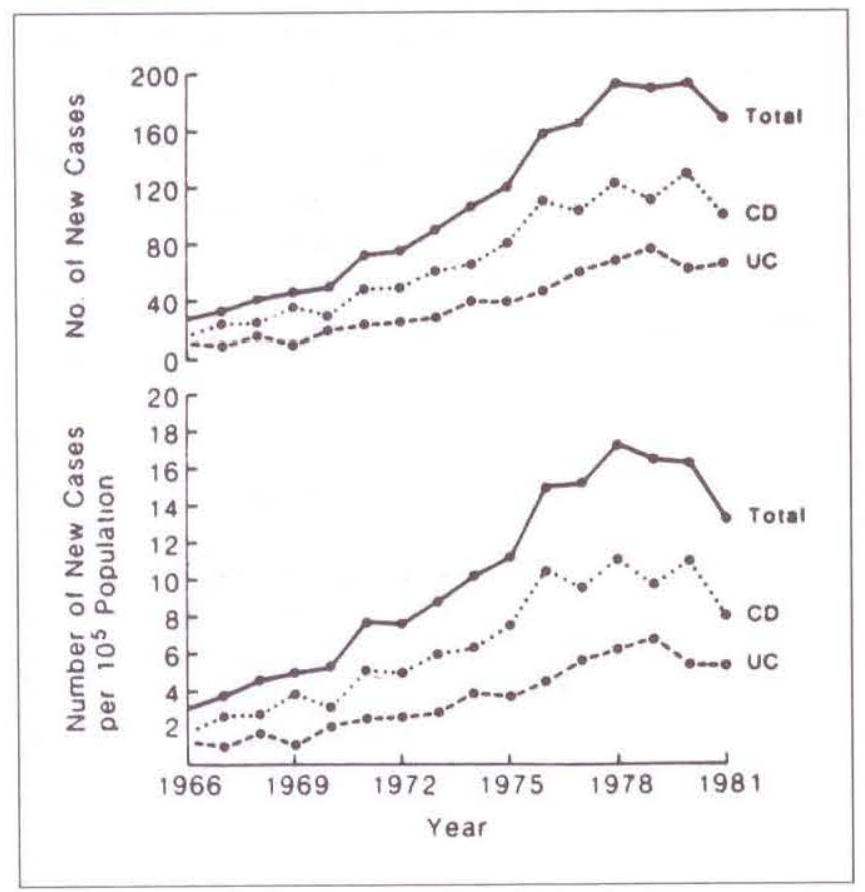

Figure 3) Influence of year and number of new patients with inflammatory bowel disease. CD Crohn's disease; UC ulcerative colitis. (Reproduced with permission from Pinchbeck et al. J Clin Gastroenterol 1988; 10:505-15)

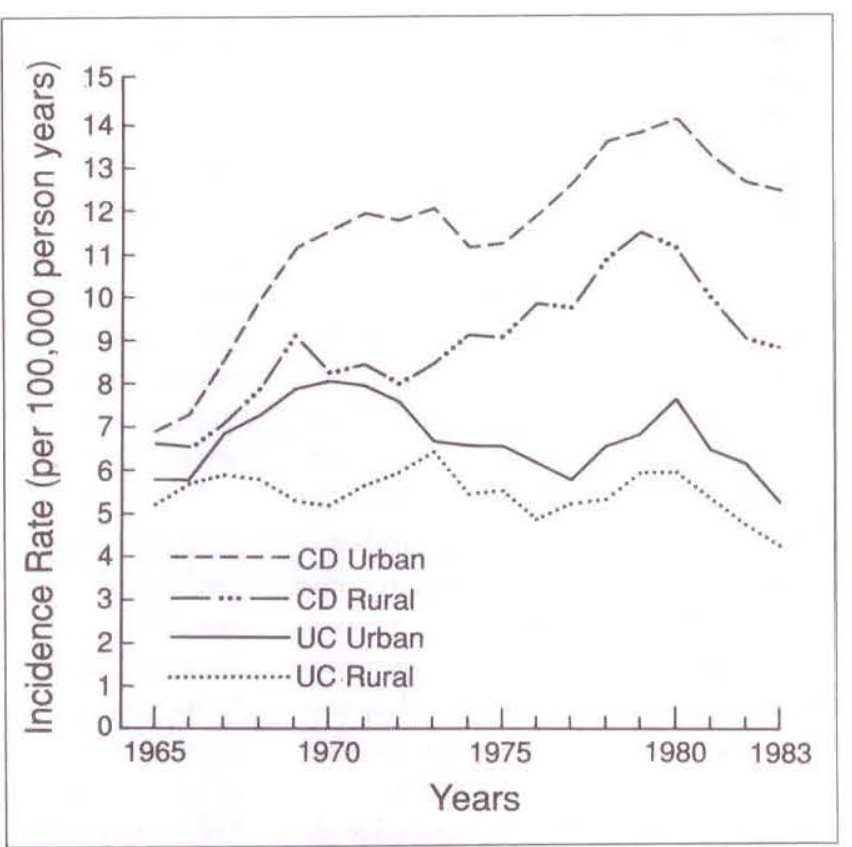

Figure 2) Age-adjusted annual incidence rates for ulcerative colitis (UC) and Crohn's disease (CD), by urban or rural residence in Uppsala, Sweden from 1965-83 (moving three-year average is adjusted to the 1970 Swedish population)

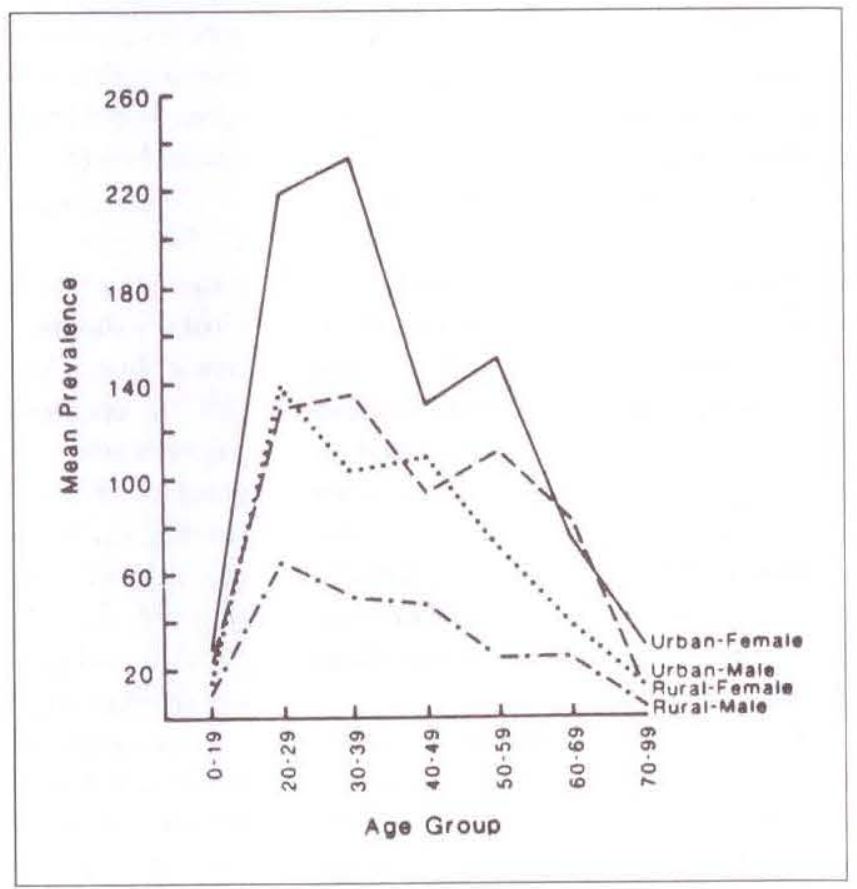

Figure 4) Influence of location of residence, sex and age of patient on mean prevalence (per 10 $0^{5}$ ) of Crohn's disease (reproduced with permission from Pinchbeck et al. J Clin Gastroenterol 1988;10:505-15)
(59) was due to more patients being diagnosed with ulcerative proctitis, rather than extensive ulcerative colitis (Figure 1). The number of ulcerative colitis patients living in an urban or a rural setting remained stable, whereas there was an increase in the number of patients with Crohn's disease (which always is higher in an urban than in a rural setting), with the incidence peak- ing in 1980 and then declining (Figure 2)(59).

Other workers (60) have suggested that the incidence of Crohn's disease is not decreasing in Sweden. From 1963 




Figure 5) Discharge rates of patients with Crohn's disease and ulcerative colitis in England/Wales between 1962 and 1985. Top: Male patients; Bottom: Female patients. The rates were adjusted to the age distribution of the 1980 population in England and Wales. (Reproduced with permission from Sonnenberg. Dig Dis Sci 1990;35:375-81)



Figure 6) Discharge rates for males and females with ulcerative colitis were reasonably stable from age 20 to over 75 years from 1971 to 1986. (Reproduced with permission from Riley R. Health Reports 1990;2:343)

until 1987, the incidence of Crohn's disease in Cardiff, Wales continued to rise (61) (as in other countries). The incidence of ulcerative colitis remained stable in Cardiff over this same period (62). In southern Alberta, the in-

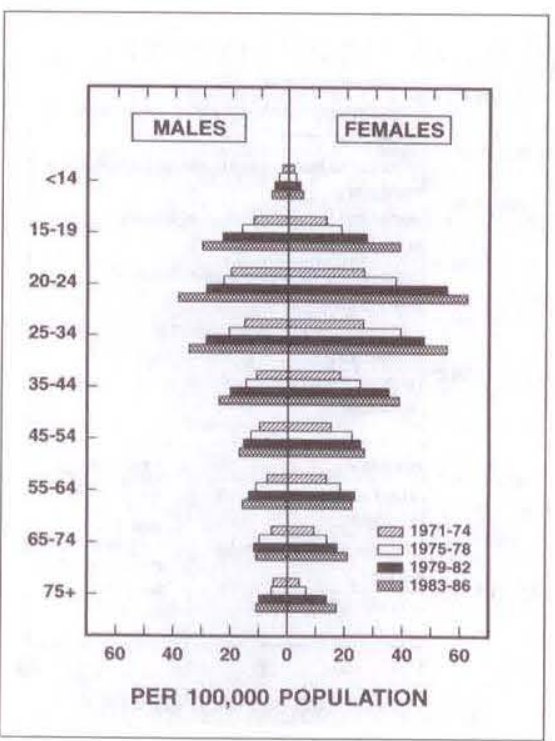

Figure 7) Age-specific discharge rates for Crohn's disease. (Reproduced with permission from Riley R. Health Reports 1990;2:343)

cidence of Crohn's disease is higher than the incidence for ulcerative colitis in both males and females (63). In northern Alberta, the incidence of both Crohn's disease and ulcerative colitis increased from the mid-1960s until 1981 (Figure 3)(22). The prevalence of ulcerative colitis was highest between the years of 20 and 60 , but there was no difference between males and females nor between urban and rural dwellers (22). In contrast, the prevalence of Crohn's disease is highest among young urban females, intermediate and equal among urban males and rural females, and lowest in rural males (Figure 4). The peak frequency of Crohn's disease in the eastern townships of Quebec also peaks at about age 30 (64), but the prevalence appears to be higher in southern and northern Alberta than in Quebec.

Hospital discharge rates: Sonnenberg (65) demonstrated that hospital discharges for ulcerative colitis in England and Wales have remained stable between 1961 and 1986, whereas the rates have increased for both males and females with Crohn's disease (Figure 5). Between 1970 and 1987 in the United States of America, the rates of hospital discharges of patients with Crohn's disease increased in both males eand females. Discharge rates for patients with ulcerative colitis remained un-

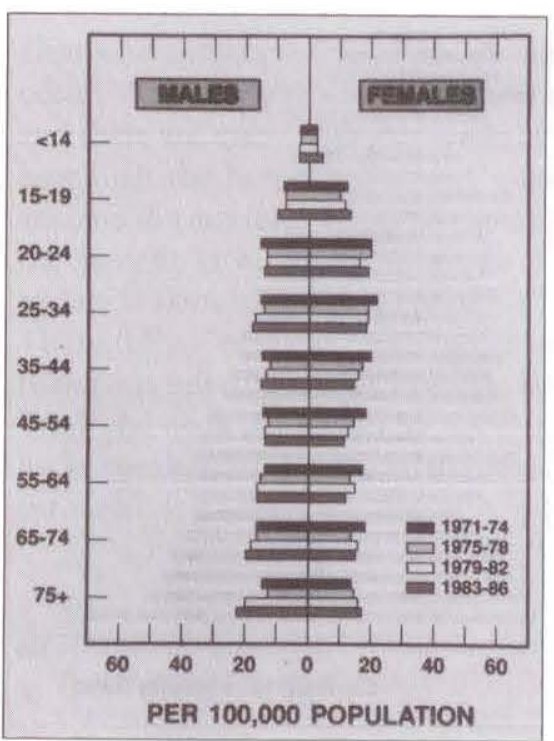

Figure 8) Age-specific discharge rates for ulcerative colitis. (Reproduced with permission from Riley R. Health Reports 1990;2:343)

changed in males, but showed a smooth rate of decline in females. The agespecific discharge rates for ulcerative colitis varied little between 1971 and 1987 in patients aged 20 and over, whereas for males and females with Crohn's disease, the age-specific discharge rates increased markedly between 1971 and 1986, and were much higher in persons aged 20 to 24 and 25 to 34 than at other ages.

Discharge rates for males and females with ulcerative colitis were reasonably stable from age 20 to 75 and over from 1971-86. Discharge rates for Crohn's disease were always higher for females than for males, were highest for ages 20 to 34 , and increased from 1971 . 86. This certainly is compatible with community-based data of the age and gender interaction in Crohn's disease.

In Canada, information on Crohn's disease and ulcerative colitis morbidity and mortality comes from the recent study by Riley (66). For Crohn's disease, age-standardized rates for hospital discharges per $10^{5}$ population between 1971 and 1986 increased by $148 \%$ for males and by $192 \%$ for females. In 1986 the rate for females was $48 \%$ higher than the rate for males, and for both males and females the age-specific discharge rates were highest in the 20 to 24 age group. For ulcerative colitis, male age-standardized discharge rates 




Figure 9) Geographic distribution of inflammatory bowel disease among caucasians in the United States's 30 largest states. Hatched and solid bars represent the standardized morbidity ratio of southern and northern states, respectively. (Reproduced with permission from Sonnenberg et al. Gastroenterology 1991;100:143)

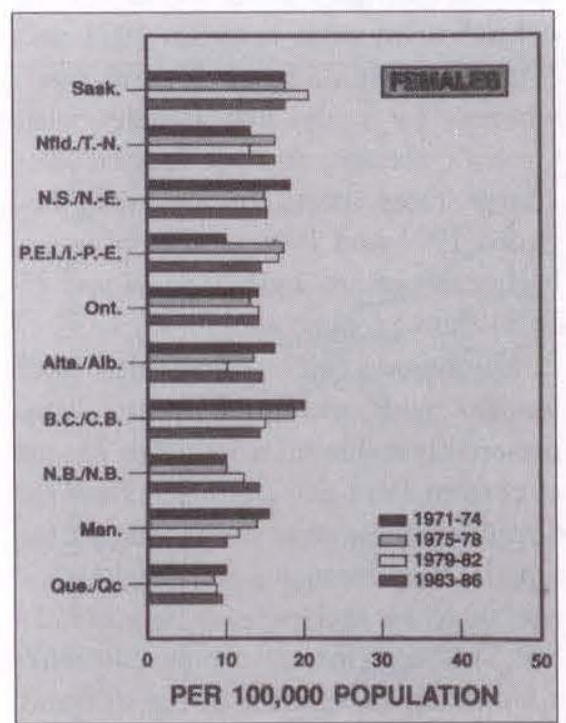

Figure 10) Discharge rates, rank ordered for females with ulcerative colitis in Canada. (Reproduced with permission from Riley $R$. Health Reports 1990;2:343)

decreased by $17 \%$ from $1971-77$, and then increased by $41 \%$ from 1977-86. For females, the rates decreased by $18 \%$ from 1971-76, then remained steady from 1976-86. The male and female ulcerative colitis discharge rates were similar over the study period, but were much higher for Crohn's disease than for ulcerative colitis, and for females



Figure 11) Discharge rates, rank ordered for females with Crohn's disease in Canada. (Reproduced with permission from Riley $R$. Health Reports 1990;2:343)

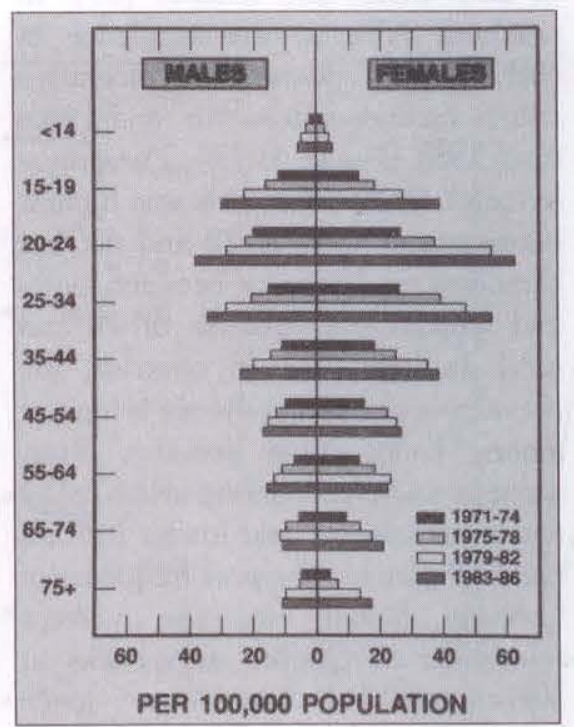

Figure 12) Age-specific mortality rates for males and females with Crohn's disease. (Reproduced with permission from Riley $R$. Health Reports 1990;2:343)

than for males (Figure 6). The agespecific discharge rates for males and females with ulcerative colitis did not vary greatly for the age groups 20 to 75 and over, and did not change much between 1971 and 1986 (Figure 7). In contrast, age-specific discharge rates were highest for Crohn's disease in the age groups 20 to 24 and 25 to 34 (for

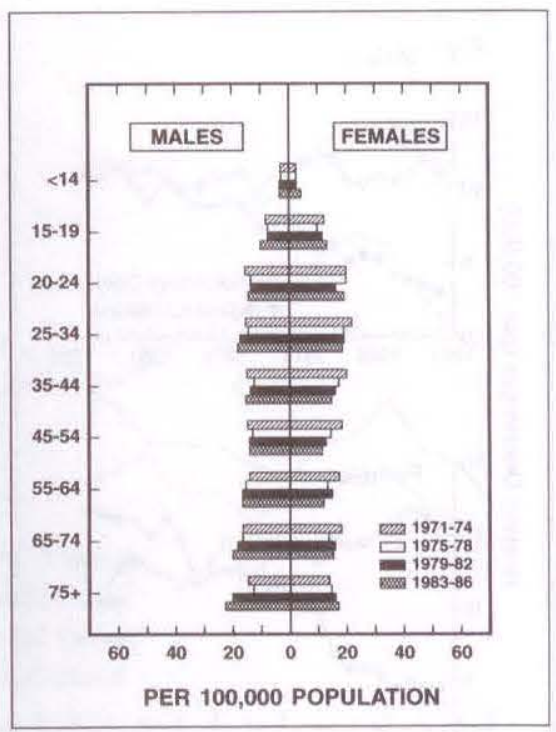

Figure 13) Age-specific mortality rates for males and females with ulcerative colitis. (Reproduced with permission from Riley R. Health Reports 1990;2:343)

males and females); these rates have increased progressively from 1971-86 (Figure 8 ) Sonnenberg and co-workers (67) noted geographic variations in the morbidity rates of IBD, with lowest values in Minnesota and highest in Massachusetts with a trend towards higher standardized morbidity ratios in the northern compared with the southern states but with no obvious difference between the western versus the eastern states (Figure 9). Discharge rates for females with ulcerative colitis were similar across Canada from 1971 . 86 (Figure 10). In sharp contrast, for females with Crohn's disease the discharge rate increased markedly over this period and were much higher in Alberta, Nova Scotia, Newfoundland, Saskatchewan and British Columbia than Ontario or Quebec (Figure 11). The reasons for these geographic varia. tions are unknown, but unlikely are related to financial considerations because of Canada's universal access health care system.

Mortality rates: The results of these community-based surveys may be substantiated by an examination of mortality rates and hospital discharge rates. Mendeloff and Dunn (68) reported that the combined mortality rate from Crohn's disease and ulcerative colitis 
was independent of race, age or gender, and was approximately one per $10^{5}$ population. The mortality rate from ulcerative colitis in northeast Scotland (69) or from Copenhagen, Denmark, (70) was no different from the general population, a finding confirmed by others (71-75). In Canada, while most of the deaths due to Crohn's disease occur in persons over the age of 45 , most deaths in ulcerative colitis occur in individuals over the age of 65 (Figures

\section{REFERENCES}

1. Ekbom A, Adami H-O. The Epidemiology of inflammatory bowel disease. In: MacDermott RP, Stenson WF, eds. Current Topics in Gastroenterology. New York: Elsevier 1992: Chapter 1.

2. Miller DS, Keighley AC, Smith PG et al. Crohn's disease in Nottingham: A search for time-space clustering. Gut 1975;16:454-7.

3. Miller DS, Keighley AC, Smith PG et al. A case control method for seeking evidence of contagion in Crohn's disease. Gastroenterology 1976;71:385-7.

4. Levine J. Exogenous factors in Crohn's disease. A critical review. J Clin Gastroenterol 1992;14:216-26.

5. Mayberry JF, Rhodes J, Allen R, et al. Diet in Crohn's disease: Two studies of current and previous habits in newly diagnosed patients. Dig Dis Sci 1981;26:444-8.

6. Whorwell PS, Holdstock G, Whorwell GM, Wright FH. Bottle feeding, early gastroenteritis, and inflammatory bowel disease. Br Med J 1979;1:382.

7. Gilat T, Hacohen D, Lilos P et al. Childhood factors in ulcerative colitis and Crohn's disease. An international cooperative study. Scand J Gastroenterol 1987;22:1009-24.

8. Bergstrand O, Hellers G. Breast-feeding during infancy in patients who later develop Crohn's disease. Scand J Gastroenterol 1983;18:903-6

9. Koletzko S, Sherman P, Corey M, et al. Role of infant feeding practices in development of Crohn's disease in childhood. Br Med J 1989;298:1617-8.

10. Shiraki K, Ishitani N, Matsuda T, et al. Epidemiologic study of ulcerative colitis and Crohn's disease in infants and children throughout country. Proceedings of Intractable Inflammatory Bowel Disease Research Group 1987;40-5, as quoted in Yoshida Y, Murata Y. Inflammatory bowel disease in Japan: Studies of epidemiology and etiopathic genesis.
12,13). Between 1971 and 1986 there was actually a decline in the number of deaths due to Crohn's disease and ulcerative colitis in persons aged 45 to 64 , but an increase was observed in those who were older.

\section{SUMMARY}

Epidemiological studies have suggested that there may be an environmental, as well as a familial, factor in the pathogenesis of IBD, but it is un-

Med Clin North Am

1990;74:67-90.

11. Martini GA, Brandes JW. Increased consumption of refined carbohydrates in patients with Crohn's disease. Klin Wochenschr 1976;54:367-71.

12. Thornton JR, Emmett PM, Heaton KW. Diet and Crohn's disease:

Characteristics of the preillness habit. Br Med J 1979;2:762-4.

13. Mayberry JF, Rhodes J, Newcombe RG. Increased sugar consumption in Crohn's disease. Digestion 1980;20:323-6.

14. Katschinski B, Logan RFA, Edmond M, Langman MR. Smoking and sugar intake are separate but interactive risk factors in Crohn's disease. Gut 1988;29:1202-6.

15. Tobin MV, Logan RFA, Langman MJS, McConnell RB, Gilmore IT. Cigarette smoking and inflammatory bowel disease. Gastroenterology 1987;93:316-21.

16. Lindberg E, Tysk C, Andersson K, Jarnerot G. Smoking and inflammatory bowel disease. A case control study. Gut 1988;29:352-7.

17. Vessey M, Jewell D, Smith A, Yeates D, McPherson K. Chronic inflammatory bowel disease, cigarette smoking, and use of oral contraceptives: Findings in a large cohort study of women of childbearing age. Br Med J 1986;292:1101-3.

18. Logan RFA, Kay CR. Oral contraception, smoking and inflammatory bowel disease - findings in the Royal College of General Practitioners Oral Contraceptive Study. Int J Epidemiol 1989;18:105-7.

19. Lesko SM, Kaufman DW, Rosenberg L, et al. Evidence for an increased risk of Crohn's disease in oral contraceptive users. Gastroenterology 1985;89:1046-9.

20. Lashner BA, Kane SV, Hanauer SB. Lack of association between oral contraceptive use and ulcerative colitis. Gastroenterology 1990;99:1032-6.

21. Lashner BA, Kane SV, Hanauer SB. clear where the next breakthrough will occur. We know who the patients are and there are many of them - we know how high the hospital discharge rates are, and the mortality rates. The cost to the patient is high, and the cost to society is alarming and increasing (76). Thankfully, medical and surgical therapy is improving, but when do we break the code, where do we get that lucky break, that long-awaited breakthrough?

Lack of association between oral contraceptive use and Crohn's disease: A community-based matched case-control study. Gastroenterology 1989;97:1442-7.

22. Pinchbeck BR, Kirdeikis J, Thomson ABR. Inflammatory bowel disease in Northern Alberta, Canada: An epidemiologic study. J Clin Gastro 1988;10:505-15.

23. Silkoff K, Hallak A, Yegena L, et al. Consumption of refined carbohydrates by patients with Crohn's disease in Tel-Aviv-Yafo. Postgrad Med J 1980;56:824-6.

24. Logan RFA, Somerville KW, Edmond $\mathrm{M}$, et al. Is cigarette smoking associated with Crohn's disease? Gut 1983;24:A980-1.

25. Somerville KW, Logan RJA, Edmond $M$ et al. Smoking and Crohn's disease. Br Med J 1984;289:954-6.

26. Franceschi S, Panza E, LaVecchia C, et al. Nonspecific inflammatory bowel disease and smoking. J Epidemiol 1987;125:445-52.

27. Holdstock G, Savage D, Harman M et al. Should patients with inflammatory bowel disease smoke? $\mathrm{Br}$ Med J 1984;298:362.

28. Sutherland LR, Rancharan S, Bryant $\mathrm{H}$, et al. Effect of cigarette smoking on recurrence of Crohn's disease. Gastroenterology 1990;98:1123-8.

29. Tysk C, Lindberg E, Jarnerot G, Foderus-Myrhed B. Ulcerative colitis and Crohn's disease in an unselected population of monozygotic and dizygotic twins. A study of heritability and the influence of smoking. Gut 1988;29:990-6.

30. Calkins BM. A meta-analysis of the role of smoking in inflammatory bowel disease. Dig Dis Sci 1989;34:1841-5.

31. Pinchbeck BR, Kirdeikis CT, Thomson ABR. Epiciemiology of ulcerative colitis and Crohn's disease. In: Gitnick G, ed. Current Gastroenterology. Boca Raton: CRC Press, 1989.

32. Bjarnason I, Fehilly B, Smethurst P, Menzies IS, Levi AJ. Importance of 
local versus systemic effects of non-steroidal anti-inflammatory drugs in increasing small intestinal permeability in man. Gut 1991;32:275-7.

33. Rooney PJ, Bjarnason I. NSAID gastropathy not just a pain in the gut! Rheumatol 1991;18:796-8. (Edit)

34. Bjarnason I, Peters TJ. Intestinal permeability, nonsteroidal anti-inflammatory drug enteropathy and inflammatory bowel disease: An overview. Gut 1989;30:22-8.

35. Rampton DS, McNeil NI, Sarner EL. Analgesic ingestion and other factors preceding relapse in ulcerative colitis. Gut 1983;24:187-9.

36. Mee AS, Jewell DP. Factors inducing relapse in inflammatory bowel disease. Br Med J 1978;2:801-2.

37. Rampton DS, Sladen GE. Relapse of ulcerative proctocolitis during treatment with non-steroidal antiinflammatory drugs. Postgrad Med ] 1981;57:297-9.

38. Imes $S$, Pinchbeck BR, Thomson ABR. Diet counselling modifies nutrient intake of patients with Crohn's disesae. J Am Dietetic Assoc 1987;87:457-62.

39. Imes $\mathrm{S}$, Pinchbeck $\mathrm{B}$, Thomson ABR Diet counselling improves the clinical course of patients with Crohn's disease. Digestion 1988;39:7-19.

40. Imes S, Pinchbeck B, Dinwoodie I, Walker K, Thomson ABR. Effect of Ensure, a defined formula diet, in patients with Crohn's disesae. Digestion 1986;35:158-69.

41. Imes S, Pinchbeck B, Dinwoodie A, Walker K, Thomson ABR. Vitamin A status in 137 patients with Crohn's disease. Digestion 1987;37:166-70.

42. Imes S, Pinchbeck BR, Dinwoodie A. Walker K, Thomson ABR. Iron, folate, vitamin B12, zinc and copper status in outpatients with Crohn's disease: Effect of diet counselling. Am Dietetic Assoc 1987;87:928-30.

43. Imes S, Dinwoodie A, Walker K, Pinchbeck B, Thomson ABR. Vitamin C status in 137 outpatients with Crohn's disease. J Clin Gastroenterol 1986;8:443-6.

44. Sullivan SN. Hypothesis revisited: Toothpaste and the cause of Crohn's disease. Lancet 1990;336:1096-7.

45. Mayberry JF, Rhodes J, Newcombe RG. Breakfast and dietary aspects of Crohn's disease. Br Med J 1978;2:1401.

46. Rawcliffe PM, Truelove SC. Breakfast and Crohn's disease. Br Med J 1978;2:539-40.

47. Pinchbeck B, Kirdeikis J, Thomson ABR. Familial prevalence of inflammatory bowel disease in Northern Albertan families. Can J Gastroenterol 1990;4(5):184-9.

48. Bennett RA, Rubin PH, Present DH. Frequency of inflammatory bowel disease in offspring of couples both presenting with inflammatory bowel disease. Gastroenterology 1991;100:1638-43.

49. Murray CIW, Thomson ABR. Marital idiopathic inflammatory bowel disease. Crohn's disease in a husband and wife. J Clin Gastroenterol 1988;10:95-7.

50. Tysk C, Riedesel H, Lindberg E, Panzini B, Podlosky D, Jarnerot G. Colonic glycoproteins in monozygotic twins with inflammatory bowel disease. Gastroenterology 1991;100:419-23.

51. Hollander D, Vadheim CM, Brettholz E, Petersen GH, Delahunty T, Rotter JI. Increased intestinal permeability in patients with Crohn's disease and their relatives. A possible etiologic factor? Ann Intern Med 1986; 105:883.

52. Katz KD, Hollander D, Vadheim CM, et al. Intestinal permeability in patients with Crohn's disease and their healthy relatives. Gastroenterology 1989;97:927-31.

53. Teachon K, Smithlovst P, Levi AS, Neuziesis, Bjarnason I. Intestinal permeability in patients with Crohn's disease and their first degree relatives. Gut 1992;33:320-3.

54. Ruttenberg D, Young GO, Wright JP, Isaacs S. PEG-400 excretion in patients with Crohn's disease, their first-degree relatives and healthy volunteers. Dig Dis Sci 1992;37:705-8.

55. Rutgeerts P, Geboes K, Vantrappen G, Beyls J, Kerremans R, Hiele M. Predictability of the postoperative course of Crohn's disease. Gastroenterology 1990;99:956-63.

56. Roley SA, Mani V, Goodman MJ, Lucas S. Why do patients with ulcerative colitis relapse? Gut 1990;31:179-83.

57. Isgar B, Harman M, Kaye MD, Whorwell PJ. Symptoms of irritable bowel syndrome in ulcerative colitis remission. Gut 1983;24:190-2.

58. Mendeloff AI. The epidemiology of inflammatory bowel disease. Clin Gastroenterol 1980;9:259-70.

59. Ekbom A, Helmick C, Zack M, Adami H-O. The epidemiology of inflammatory bowel disease: A large, population-based study in Sweden. Gastroenterology 1991;100:350-8.

60. Lindberg $E$, Jarnerot $G$. The incidence of Crohn's disease is not decreasing in Sweden. Scand J Gastroenterol 1991;26:495-500.

61. Rose J-DR, Roberts GM, Williams G,
Mayberry JF, Rhodes J. Cardiff Crohn's disease jubilee: The incidence over 50 years. Gut 1988;29:346-51.

62. Srivastava ED, Mayberry JF, Morris TJ, et al. Incidence of ulcerative colitis in Cardiff over 20 years: $1968-87$. Gut $1991 ; 33: 256-8$

63. Davis FG, Grace MG, Hershfield N. Inflammatory bowel disease incidence and prevalence in southern Alberta. Can J Gastroenterol 1990;4:187-92.

64. Nootens J, Devroede G. Fréquence de l'entérite regionale dans les cantons de l'est. L'union médicale du Canada 1972;101:1138-40.

65. Sonnenberg A. Hospital discharges for inflammatory bowel disease. Dig Dis Sci 1990;35:375-81.

66. Riley R. Crohn's disease and ulcerative colitis: Morbidity and mortality. Health Reports 1990;2:343-54.

67. Sonnenberg A, McCarty DJ, Jacobsen SJ. Geographic variation of inflammatory bowel disease within the United States. Gastroenterology 1991;100:143-9.

68. Mendeloff AI, Dunn JP. Digestive Diseases. American Public Health Association Vital and Health Statistics Monograph. Cambridge: Harvard University Press, 1971.

69. Sinclair TS, Brunt PW, Mowat NAG. Non-specific proctocolitis Northeastern Scotland: a community study. Gastroenterology 1983;85:1-11.

70. Hendriksen C, Kreiner S, Binder V. Long-term prognosis in ulcerative colitis - based on results from a regional patient group from the county of Copenhagen. Gut 1985;26:158-63.

71. Edwards FC, Truelove SC. The course and prognosis of ulcerative colitis. Parts I and II. Gut 1963;4:299-315.

72. Jalan KU, Prescott PJ, Sircus W, et al. An experience of ulcerative colitis. Parts I and II. Gastroenterology 1970;65:589-609.

73. Ritchie JK, Powell-Tuck J, LennardJones JE. Clinical outcome of the first ten years of ulcerative colitis and proctitis. Lancet 1978;i:1140-3.

74. Hellers G. Crohn's disease in Stockholm County, 1955-1974. Acta Chir Scand 1979;490(suppl):1-84.

75. Binder V, Both H, Hansen PK, Hendriksen C, Kreiner S, Torp Pedersen K. Incidence and prevalence of ulcerative colitis and Crohn's disease in the County of Copenhagen 1962-1978. Gastroenterology 1982;83:563-8.

76. Pinchbeck BR, Kirdeikis J, Thomson ABR. Economic impact of inflammatory bowel disease in Alberta, Can J Gastroenterol 1988;2:53-6. 


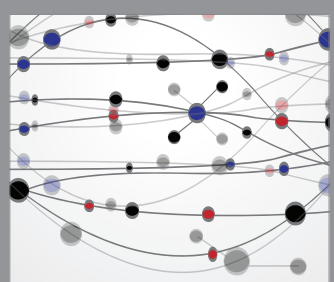

The Scientific World Journal
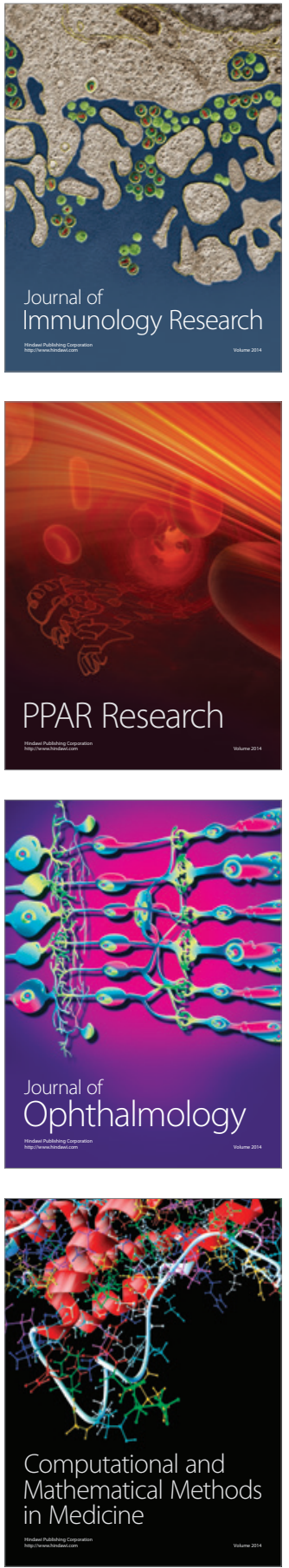

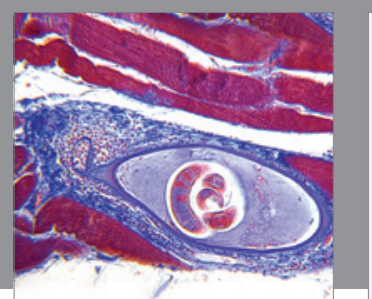

Gastroenterology Research and Practice



\section{Hindawi}

Submit your manuscripts at

http://www.hindawi.com

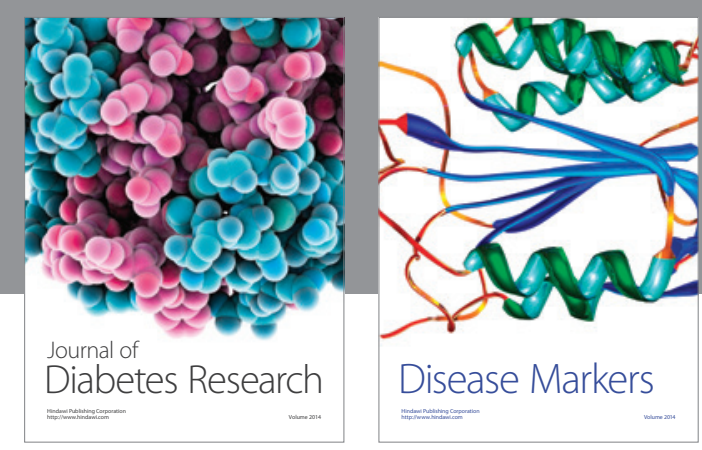

Disease Markers
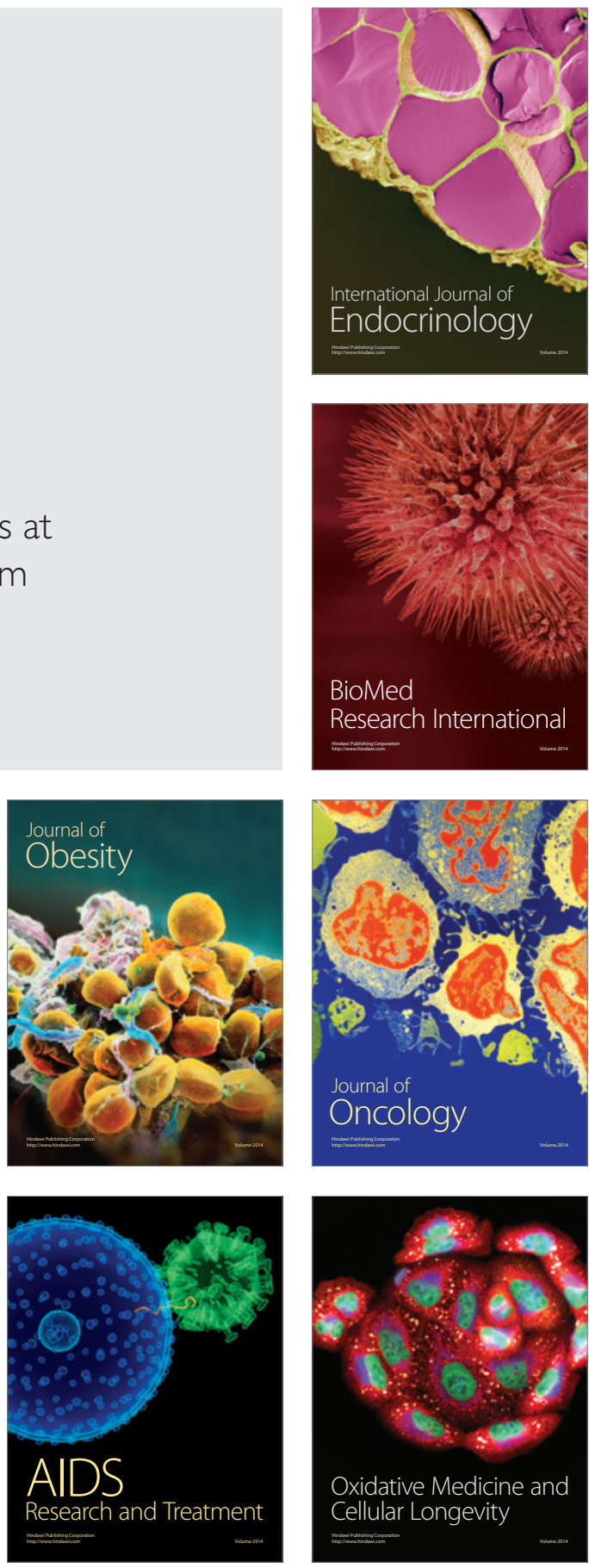